\title{
EVALUATING THE POTENTIAL FOR LOW ENERGY EMITTERS TO FACILITATE SOLAR-POWERED DRIP IRRIGATION IN SUB-SAHARAN AFRICA
}

\author{
G. Van de Zande ${ }^{凶}$, S. Amrose and A. G. Winter \\ Massachusetts Institute of Technology, United States of America \\ $\bigotimes$ gdvdz@mit.edu
}

\begin{abstract}
Introducing irrigation to smallholder farms in Sub-Saharan Africa (SSA) can increase food security, improve nutrition, and reduce poverty. To explore the possibility of using drip irrigation on smallholder farms in SSA, we introduce a feasibility study that views the design space from both a user-centered lens, explaining how drip might be successful in the future, and from an engineering lens. With a firstorder model, we compare estimated capital costs of drip and sprinkler systems for various farm profiles and show that drip has the potential to be a viable technology for many farms in SSA.
\end{abstract}

Keywords: sustainable design, energy efficiency, engineering design, technology development

\section{Introduction and motivation}

The objective of this work is to assess the potential for novel, low-energy drip emitters to act as an enabling technology for solar-powered drip irrigation in Sub-Saharan Africa (SSA). Numerous studies have shown the potential benefits of introducing irrigation on smallholder farms in SSA (Amede, 2015; Hagos et al., 2012; Mati, 2008; Ngigi et al., 2001; Shah et al., 2013). Irrigation enables additional cropping seasons per year, and it allows farmers to cultivate fruits, vegetables, and other more nutritious, higher-value crops that require reliable water sources (Burney et al., 2010). Less dependence on rainfed agriculture makes communities more resilient against periods of water scarcity. Recently, solar-powered irrigation systems have been promoted throughout SSA through various government programs and subsidies and were demonstrated to be economically viable compared to diesel and grid powered systems in a variety of locations (Ali, 2018; Otoo et al., n.d.; Schmitter et al., 2018; Yamegueu et al., 2019). These systems are particularly attractive in rural areas where diesel fuel is expensive and there is often no reliable access to the electricity grid (Pavelic et al., 2013).

Drip irrigation is a method of delivering water directly to the roots of the crop through a network of pipes and drip emitters. It facilitates cost reductions by reducing the amount of water lost to evaporation and deep percolation, thereby reducing the amount of water that must be pumped from a water source. This, in turn, reduces the capital cost of the required pump and solar power system. It also may be easier for farmers to profit from a drip system compared to a furrow irrigated system due to reduced labour costs and increased crop options, particularly of higher value crops (FAO et al., 2017). However, for solar-powered drip irrigation to be viable, all of these cost benefits must outweigh the high upfront costs of the drip equipment (pipes, fittings, and emitters). In SSA, these high upfront costs of drip have remained a key barrier limiting its adoption (FAO et al., 2017). 
A large component of the high upfront cost of solar-powered drip irrigation comes from the capital cost of the pump and solar power system required to pressurize the pipe network. The largest pressure losses in a conventional drip irrigation system fed by a surface water source are due to the drip emitters themselves (Shamshery and Winter, 2018), particularly in the case of pressure-compensating (PC) drip emitters, which are emitters that maintain a nearly constant flow rate once a minimum activation pressure is reached. The MIT Global Energy and Research (GEAR) Lab recently developed a novel, low-energy PC drip emitter with an activation pressure of $0.15 \pm 0.05$ bar ( $1.5 \pm 0.5 \mathrm{~m}$ head), an $83 \%$ reduction compared to commercially available emitters (Shamshery and Winter, 2018). For many small farmers using surface water sources, low-energy emitters could lower the capital cost of a solar-powered drip system by up to $40 \%$ (based on Indian prices) (Shamshery and Winter, 2018). This emitter technology was recently demonstrated across nine sites in Jordan and Morocco and was found to use an average of $43 \%$ less hydraulic energy than locally purchased conventional emitters (Sokol et al., 2019). A systems-level optimization of solar-powered drip irrigation systems in the Middle East and North Africa (MENA) region revealed additional cost-saving opportunities through adjustments in irrigation practices, such as reducing the flow rate of the emitters (Grant, 2019; Sheline, 2019).

The potential for low-energy drip technology to address barriers to drip adoption and act as an enabling technology for solar-powered irrigation in SSA is unknown. This paper takes a first step to understand the potential enabling capacity of low-energy drip in such a context. To explore the potential of cost-saving strategies that might be applicable in SSA, and to develop a preliminary understanding of the barriers to drip adoption in several diverse countries, a series interviews with farmers and key stakeholders in the irrigation market were conducted in Kenya, Ethiopia, and Zambia in 2019. In particular, the interviews sought to understand the potential acceptability of a low-energy drip emitter with a very low flow rate, which would require irrigating over longer durations than current practice. Operating at low flow rates can reduce power consumption because power scales with flow rate. Thus, delivering the same amount of water with a lower flow rate results in a less expensive pump and solar power system. However, this design change can have large implications on the user experience, as it would increase daily irrigation time for farmers. Interview questions were designed to understand how much farmers were willing to increase irrigation time in exchange for these cost-saving benefits. Additional questions with farmers and stakeholders were aimed at understanding the potential drip adoption barriers and representative conditions to inform energetic and economic analyses.

To assess ability of low-energy emitters to address the upfront cost barrier of drip adoption, preliminary economic and energetic analyses of low-energy drip systems (hereafter referred to as "LE drip systems") were performed. The cost and power consumption of drip is compared to low-cost impact sprinklers, which have recently seen significant and growing market penetration in conjunction with solar-powered irrigation systems sold in Kenya (e.g. the RainMaker2 by SunCulture, 2020, or SF2 by FuturePump, 2020). These analyses compare the capital costs and power consumption of LE drip systems to those of sprinkler systems.

The overall objective of this work is to build an understanding of the potential that low-energy drip emitter technology has to act as an enabling technology for solar-powered drip irrigation in SSA by:

- Understanding potential barriers to adoption and user constraints given the opportunities afforded by LE drip systems, in particular long operation times at low flow rates

- Exploring the potential impact of low energy drip emitters in SSA markets by comparing the economics of LE drip systems to those of impact sprinkler systems

The outcome of this work will be a preliminary understanding of whether low-energy drip emitters could potentially have a positive impact on the SSA market for solar-powered drip irrigation, and provide justification for a more detailed analysis to explore viability and acceptability.

\section{Methods}

\subsection{Farmer and stakeholder interviews}

This research used a three-phase qualitative and quantitative approach to gain information about the Kenyan, Ethiopian, and Zambian irrigation markets. In the first phase, semi-structured interviews with 
key stakeholders were conducted in January 2019, including private companies that sell irrigation systems, governmental agencies, non-governmental organizations (NGOs), research institutions, and micro-finance institutions (MFIs). The intention of these interviews was to understand the current state of the smallholder irrigation, drip irrigation, and solar-powered irrigation in these countries from policy and market perspectives. During the interviews, parameters such as typical field sizes and water requirements of commonly grown crops were gathered to inform the model described in Section 2.2.

In the second phase, seventeen in-depth, semi-structured interviews were conducted with smallholder farmers in Kenya, Ethiopia, and Zambia in January 2019. Farmers were recruited through either private companies or NGOs who had sold or provided irrigation systems to the farmers. While all seventeen farmers were experienced with irrigation, only eleven had experience with drip irrigation in particular. In all farmer interviews, participants were asked about their experience with farming, their current and former irrigation equipment, their likes and dislikes with regard to drip irrigation (if applicable), their irrigation schedules, finances related to their farming businesses, and their plans for expansion. In the third phase, eight in-depth, structured interviews were conducted in August 2019 with smallholder farmers in Kenya, all of whom had been product testing a private company's new drip kit for 4-5 months. The kit, consisting of a 250 square meter pipe network, had been given to the farmers by the company. The farmer interview protocols were approved by the Massachusetts Institute of Technology Institutional Review Board.

\subsection{Engineering estimation approach}

\subsubsection{A model for estimating power and capital cost of LE drip and sprinkler systems}

A model was built to conduct first-order estimations of the power and capital cost of solar-powered LE drip and impact sprinkler irrigation systems for a variety of farm profiles (defined by field size and groundwater depth). LE drip systems were compared to impact sprinkler systems, modelled after the impact sprinkler sold by SunCulture, a solar irrigation company in Kenya. The farm profiles tested in this model had field sizes in the range of $0.01-0.5$ ha, with a step of 0.01 ha. This field area range was chosen to represent medium-sized smallholder farms similar to those encountered during interviews. A range of groundwater sources 0 - $30 \mathrm{~m}$ deep were tested, stepped by $1 \mathrm{~m}$ increments.

For each combination of field size and groundwater depth, the power required and the estimated system capital cost were calculated using the additional farm profile input parameters shown in Table 1. Representative, baseline values of these parameters were estimated from average values collected from interviews or taken from literature.

The Ethiopian Ministry of Agriculture advises farmers to use an average of $6.7 \mathrm{~mm}$ of water each day to grow tomatoes, a common crop (Kebede and Birru, 2018). The water volume correction factor accounts for the assumption that farms using drip irrigation can deliver up to $70 \%$ less water than farms using sprinkler irrigation (Allen et al., 1998). The available irrigation time describes the duration of time that a pump could be in operation in a day. Assuming that only solar panels power the systems, the irrigation time is limited to 8 hours of sunlight a day. The model is simplified to assume a constant level of irradiance is given throughout the day. Market research shows that a solar panel cost of 1.50 USD/W is a reasonable price for small-scale solar panels in Kenya (Hartung and Pluschke, 2018). This model uses an estimated pump efficiency of 0.3 or $30 \%$, a common value for a system in this market. SunCulture offers 250 square meter drip kits for about $100 \mathrm{USD}$, or $4000 \mathrm{USD} / \mathrm{ha}$, and these numbers were used as a baseline. Based on stakeholder interviews, impact sprinklers sell for a maximum of about $100 \mathrm{USD} / \mathrm{ha}$.

A hydraulic model of LE drip irrigation pipe networks, described fully in Sokol et al. (2018), estimates that 0.1 ha coverage of LE drip equipment requires approximately $3 \mathrm{~m}$ of pressure head to activate the hydraulic network. This value takes the activation pressure of GEAR Lab low-energy drip emitters into account, and thus $3 \mathrm{~m}$ is a lower value than would be expected from commercially available emitters. From several interviews, it was learned that impact sprinklers in Kenya typically operate at pressures of $\sim 25 \mathrm{~m}$ of head over a coverage area of at least 0.03 ha. Assuming there are three impact sprinklers used at a given time (typical practice), the operating pressure remains $\sim 25 \mathrm{~m}$, but the covered area reaches 0.1 ha. 
Table 1. Farm profile input parameters, estimated baseline values, units, and symbols used in the power and capital cost estimations. Lower and upper limits are used in a sensitivity analysis to understand the influence of these parameters on the capital cost estimations

\begin{tabular}{|c|c|c|c|c|c|}
\hline Parameter & Baseline value & $\begin{array}{l}\text { Lower } \\
\text { limit }\end{array}$ & $\begin{array}{l}\text { Upper } \\
\text { limit }\end{array}$ & Unit & Symbol \\
\hline Field size & 0.5 & 0.25 & 0.75 & ha & $A$ \\
\hline Groundwater depth & 20 & 10 & 30 & $\mathrm{~m}$ & $h_{\text {well }}$ \\
\hline Crop water requirement & 7 & 4 & 10 & $\mathrm{~mm} / \mathrm{day}$ & $C W R$ \\
\hline Water volume correction factor (drip) & 0.3 & 0.15 & 0.6 & -- & $V C F$ \\
\hline Water volume correction factor (sprinkler) & 1.0 & 0.8 & 1.2 & -- & $V C F$ \\
\hline Available irrigation time & 8 & 4 & 12 & hr/day & $T$ \\
\hline Additional pressure head (drip) & 3 & 1 & 6 & $\mathrm{~m}$ & $h_{\text {equip. }}$. \\
\hline Additional pressure head (sprinkler) & 25 & 15 & 35 & $\mathrm{~m}$ & $h_{\text {equip. }}$ \\
\hline Pump efficiency & 0.3 & 0.2 & 0.4 & -- & $\eta$ \\
\hline Solar panel capital cost & 1.50 & 1.00 & 2.00 & USD/W & $\frac{\text { Cost }}{\text { Watt }}_{\text {panel }}$ \\
\hline $\begin{array}{l}\text { Irrigation equipment capital cost per area } \\
\text { (drip) }\end{array}$ & 4000 & 2500 & 5500 & USD/ha & $\frac{\text { Cost }}{\text { area }}_{\text {equip. }}$ \\
\hline $\begin{array}{l}\text { Irrigation equipment capital cost per area } \\
\text { (sprinkler) }\end{array}$ & 100 & 50 & 150 & USD/ha & $\frac{\text { Cost }}{\text { area }}_{\text {equip. }}$ \\
\hline
\end{tabular}

In both the LE drip and sprinkler cases, this first-order model assumes that additional pressure head is independent of field size. In practice, this is not the case, but it was assumed that these effects would be negligible to first-order. This model also neglects pressure drops over the filter and fertigation units, as these pressure drops were assumed to be small relative to the other pressure drops in the system.

The model assumes that farmers will expand irrigated areas on their farms by increasing the number of hours they irrigate in one day up to the maximum 8 hours of sunlight, all while keeping a constant flow rate. For example, if a farmer owns 0.5 ha of cultivatable land, they may begin by irrigating a quarter of that land, 0.125 ha, for 2 hours a day. If they wish to expand to the full 0.5 ha, they would use the full 8 hours each day at the same flow rate. This assumption was consistent with results from farmer interviews (discussed further in Section 3).

To model the power consumed by each irrigation system under these assumptions, a total irrigation time is defined that is scaled by the field size. Equation (1) scales the total irrigation time $T$ [hr] to $T^{*}$ [hr] by a fraction of the field size $A$ [ha] over the maximum field size $A_{\max }$ [ha]:

$$
T^{*}=T * \frac{A}{A_{\max }} \text {. }
$$

For the various farm sizes and groundwater depths, the input parameters in Table 1 were used to calculate the power needed and estimated capital costs of irrigation systems using Equations (2-4). The power needed $P[\mathrm{~W}]$ is given by

$$
\begin{aligned}
& P=\frac{\left(C W R_{\text {vol }} * A * V C F * \rho\right) * \mathrm{~g} *\left(h_{\text {well }}+h_{\text {equip }}\right)}{\eta * T^{*}} \\
& P=\frac{1}{\eta * T} *\left(C W R_{\text {vol }} * V C F * \rho\right) * \mathrm{~g} *\left(h_{\text {well }}+h_{\text {equip. }}\right) * A_{\text {max }}
\end{aligned}
$$

where $\rho=1000 \frac{\mathrm{kg}}{\mathrm{m}^{3}}$ is the density of water and $g=9.8 \frac{\mathrm{m}}{\mathrm{s}^{2}}$ is the acceleration due to gravity. The estimated system capital cost Cost $_{\text {capital }}$ [USD] is given by

$$
\text { Cost }_{\text {capital }}=\left\{\text { [ost }_{\text {Watt }_{\text {panel }}} * P\right\}+\left\{{\frac{\text { cost }}{\text { Area }_{\text {equip. }}}}_{\text {en }} * A\right\} \text {. }
$$


Costs of the pump, battery, tank, filter, fertigation unit, and replacement costs of irrigation equipment were not included in this preliminary assessment, but will be considered in a future version of the model. Additionally, the revenue a farmer might expect from using this irrigation system is not incorporated into the model. As many farmers are ultimately motivated by their profits, future versions of this model will estimate profit as well. To make a preliminary assessment market competitiveness based on this estimation of LE drip system capital costs, these costs are compared to the capital costs of sprinkler systems, which are a viable and currently profitable product in the Kenyan market.

\subsubsection{Sensitivity analysis to input parameters}

A sensitivity analysis was performed to input parameters around the baseline case for both LE drip and sprinkler systems (lower and upper limits in Table 1). In this analysis, one parameter was varied to its lower or upper limit, while all other parameters were held at their baseline values. Because the additional pressure head for LE drip was calculated using low-energy emitters, the lower limit of this parameter is not expected to be much lower than the baseline value. The upper limit of $6 \mathrm{~m}$ is relatively higher to be more representative of conventional drip emitters. Sprinklers are available for many different operating pressures, so a large range was explored in the sensitivity analysis. The remaining limits were defined by ranges that encompass changes of $50-200 \%$ of the baseline values. Jain Irrigation, Ltd. sells drip tape in India for $2500 \mathrm{USD} / \mathrm{ha}$, which drove the lower limit of the irrigation equipment capital cost per area for drip (Patil, 2019).

\section{Results and discussion}

\subsection{Findings from farmer and stakeholder interviews}

Interviews focused on farmers' willingness to spend more time irrigating in exchange for the benefit of a reduced cost system or increased irrigated area. Many farmers noted they would be willing to increase their daily irrigation time in exchange for expanding the area irrigated on their farms. Those who were not willing noted limitations such as water scarcity which limited their expansion potential; they did not cite unwillingness to spend the time irrigating as a reason. Interviews also revealed that farmers care much more about the active time they spend on irrigation tasks and less about the total time an irrigation system runs. This was a very positive initial response, and suggested that the idea of reducing flow rates to reduce costs should be explored further.

The conducted interviews also identified several training approaches used to introduce drip irrigation to first time users. Table 2 summarizes the approaches and key observations made from each group of interviewees. It was observed that the SunCulture and Water4 training approaches were more successful than the Ethiopian extension agency training program. Although the sample size is small, this suggests that such high levels of high contact support may be an important component of successful drip adoption.

However, it was noted that quality training comes at a cost. Water4 could not support their training program through equipment sales alone. They operate under a hybrid non-profit and for-profit model, with training covered by non-profit activities. Some companies selling more expensive systems and offering high quality training have system prices that are too high for many farmers. This creates an opportunity to develop new, lower cost models of providing training and support. One possible example is a growth strategy embedded in the design of a family of irrigation systems. This would consist of a prescribed ladder of technologies a farmer would adopt before using drip that would each teach a critical skill necessary for successful drip management (e.g. irrigation scheduling or equipment maintenance).

It was also observed that the active time that a farmer spends on drip irrigation tasks could potentially be reduced with proper training on drip equipment. From interviews, farmers care more about the active time they spend on irrigation tasks (as opposed to the time that an irrigation system is running), leading to the opportunity to use a training-focused growth strategy to promote a low flow rate, costreducing LE drip system in the SSA market.

The findings from interviews with non-farmer stakeholders were consistent with other researchers who have found cost to be a major barrier to drip adoption (Blank et al., 2002). A possible solution suggested 
by various stakeholders was to reduce the capital costs of irrigation systems while at the same time improving access to credit. This could allow SSA to benefit from the benefits drip has to offer.

Table 2. Training programs of and key observations made from each group of interviewees

\begin{tabular}{|c|c|c|}
\hline $\begin{array}{l}\text { Interviewee } \\
\text { group }\end{array}$ & Description of training approach & Key observations \\
\hline $\begin{array}{l}\text { Ethiopian } \\
\text { farmers }\end{array}$ & $\begin{array}{l}\text { A government extension agency provided } \\
\text { drip training to farmers on a government- } \\
\text { owned farm for six months. The group of } \\
\text { twenty farmers divided the income from the } \\
\text { farm among themselves once the season was } \\
\text { finished. The drip tape used in this farm was } \\
\text { of much poorer quality than was seen in } \\
\text { Kenya. }\end{array}$ & $\begin{array}{l}\text { Now a dis-adopter of drip, one interviewed } \\
\text { farmer from this group noted that he didn't } \\
\text { see the value in using drip because the } \\
\text { maintenance was so difficult. } \\
\text { The government project stopped once the } \\
\text { training was finished, so there was no longer } \\
\text { support if the farmers installed drip on their } \\
\text { own farms. }\end{array}$ \\
\hline $\begin{array}{l}\text { Kenyan } \\
\text { SunCulture } \\
\text { farmers with } \\
\text { only } \\
\text { sprinkler } \\
\text { experience }\end{array}$ & $\begin{array}{l}\text { Upon installation, a trained technician } \\
\text { showed farmers how the sprinkler system } \\
\text { worked and demonstrated basic maintenance } \\
\text { steps. For farmers that purchase a TV along } \\
\text { with their system, Shamba Shape Up video } \\
\text { tutorials come preinstalled. }\end{array}$ & $\begin{array}{l}\text { These farmers expressed greater satisfaction } \\
\text { and reported higher profits compared to } \\
\text { Ethiopian farmers. } \\
\text { Many farmers claim to have used Shamba } \\
\text { Shape Up to help teach them new farming } \\
\text { techniques. }\end{array}$ \\
\hline $\begin{array}{l}\text { Kenyan } \\
\text { SunCulture } \\
\text { farmers with } \\
\text { drip and } \\
\text { sprinkler } \\
\text { experience }\end{array}$ & $\begin{array}{l}\text { In addition to the sprinkler training described } \\
\text { above, SunCulture provided } 250 \text { square } \\
\text { meter drip kits to these farmers for product } \\
\text { testing. At installation, trained technicians } \\
\text { showed farmers how the drip system worked } \\
\text { and demonstrated basic maintenance steps. }\end{array}$ & $\begin{array}{l}\text { Farmers they seemed to adopt drip well } \\
\text { because they already had above average } \\
\text { experience with irrigation technology. } \\
\text { These farmers expressed greater satisfaction } \\
\text { and reported higher profits compared to } \\
\text { Ethiopian farmers. } \\
\text { These farmers have continued using drip after } \\
\text { the first season. }\end{array}$ \\
\hline $\begin{array}{l}\text { Zambian } \\
\text { Water4 } \\
\text { farmers }\end{array}$ & $\begin{array}{l}\text { Water } 4 \text { used a novel embedded training } \\
\text { approach where farmers train for } 9 \text { months } \\
\text { on a Water4-owned farm. Farmers are then } \\
\text { continually supported by the NGO if they } \\
\text { purchase a drip system and use it on their } \\
\text { own farms. }\end{array}$ & $\begin{array}{l}\text { These farmers expressed greater satisfaction } \\
\text { and reported higher profits compared to } \\
\text { Ethiopian farmers. } \\
\text { These farmers have continued using drip after } \\
\text { the first season. }\end{array}$ \\
\hline $\begin{array}{l}\text { Farmers in } \\
\text { water scare } \\
\text { areas using } \\
\text { drip }\end{array}$ & $\begin{array}{l}\text { This group is comprised of Rift Valley } \\
\text { Ethiopian farmers and SunCulture farmers in } \\
\text { the Nanyuki area of Kenya. }\end{array}$ & $\begin{array}{l}\text { Drip benefits farmers in water scarce areas } \\
\text { In Nanyuki, multiple farmers commented that } \\
\text { their well goes dry within a few hours of } \\
\text { using sprinklers. Since installing drip, they } \\
\text { have been able to irrigate more land area with } \\
\text { this water volume constraint. }\end{array}$ \\
\hline $\begin{array}{l}\text { Non-farmer } \\
\text { stakeholders: } \\
\text { government } \\
\text { agencies, } \\
\text { NGOs, } \\
\text { MFIs, and } \\
\text { research } \\
\text { organizations }\end{array}$ & N/A & $\begin{array}{l}\text { Drip is considered to be one of the most } \\
\text { expensive options, and that cost is a major } \\
\text { barrier to adoption. } \\
\text { High capital costs pose additional barriers to } \\
\text { farmers without access to credit, which many } \\
\text { stakeholders noted was the case for farmers } \\
\text { in their areas. }\end{array}$ \\
\hline
\end{tabular}

\subsection{Engineering estimation approach}

\subsubsection{Power and capital cost comparisons for varying field sizes and groundwater depths}

The results for the power used by LE drip and sprinkler irrigation systems for various farm profiles demonstrate that for all combinations of field size and groundwater depth under the current assumptions, sprinkler systems use more power than LE drip systems (Figure 1a). Due to a higher 
$V C F$, sprinkler systems deliver more water than an LE drip system. The sprinklers used in the model also have higher additional pressure heads, $h_{\text {equip. }}$, than the drip emitters. Increased $V C F$ and $h_{\text {equip. }}$. both contribute to increased power (Equation 3).
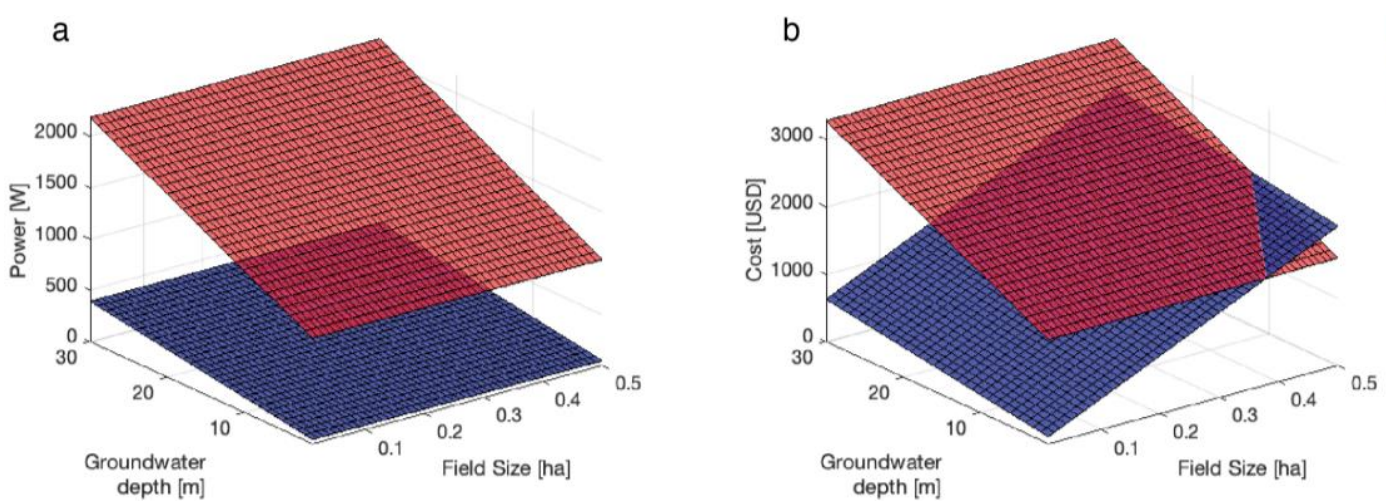

Sprinkler Drip

Figure 1. (a) Power used by drip and sprinkler irrigation systems for various farm profiles and (b) the estimated capital costs of the corresponding systems

Figure 1a shows that power is independent of field size, a result of assuming how farmers expand their land (Equation 1). This assumption presumes that a farmer would purchase all the needed solar panels before expanding to the maximum field size, so as the irrigated area of the farm grows, no additional power is needed. Only additional irrigation equipment is needed for expansion, at the cost of increased irrigation time (Equation 4). Figure $1 \mathrm{~b}$ reflects this expansion assumption, presenting the estimated capital cost of LE drip and sprinkler irrigation systems for various farm profiles.

LE drip systems are less expensive than sprinkler systems under the current assumptions for most conditions, with exceptions near maximum field sizes and at low groundwater depths. As groundwater depths increase, more energy (and therefore more power) is needed to lift water from the ground. The power cost of a sprinkler system increases faster with increasing depth than that of a LE drip system because the volume correction factor $V C F$ (and therefore the volume of pumped water) is higher for sprinklers. The higher solar panel cost required to produce the higher power in sprinkler systems outweighs the lower cost of irrigation equipment, contributing to a higher total capital cost.

To validate the model, predicted costs were compared to the SunCulture RainMaker2 (an 1100 USD sprinkler system with a flow rate of $850 \mathrm{~L} / \mathrm{hr}$ at a well depth of $20 \mathrm{~m}$ ). The model predicted cost for the RainMaker 2 is 550 USD. A low estimated cost of 550 USD validates the model to predict the cost of a sprinkler system to the first order because the model neglects certain component costs (pump, battery, tank, filter, and fertigation unit) as well as the pressure drops over these components. Under these low flow rate conditions, the model estimates an LE drip system cost of 480 USD, however, there isn't a similar system sold on the market to compare to for the LE drip system case. While this model validation was conducted under lower flow rates than the flow rate dictated by the parameters in Table 1, it is assumed that the model will remain valid to the first order if the flow rate is increased. Drip irrigation systems are generally considered much more expensive than systems using other irrigation methods. However, the results from this model indicate that low-energy drip emitters may enable LE drip irrigation to become competitive or even less expensive than irrigation methods, for certain farm profiles, making the case for further investigation into this design space. Especially for farmers with deeper wells, there is the potential for LE drip technology to reduce upfront cost barriers to purchasing irrigation systems in SSA. Ultimately, this could have positive impacts on the livelihoods of smallholder farmers in the region.

\subsubsection{Sensitivity analysis to farm profile input parameters}

Figure 2 shows the cost sensitivity to various farm profile input parameters based on the first-order cost model. The estimated capital cost for LE drip and sprinkler systems using the baseline parameters (Table 1) are 2410 USD and 2730 USD, respectively. From Figure 2, LE drip irrigation systems are much less sensitive to changes in groundwater depth, crop water requirement, available irrigation 
time, pump efficiency, and solar panel capital cost than sprinkler irrigation systems are. These parameters all relate directly to the power required by the irrigation system (Equation 3). Large fluctuations in power-related parameters influence the capital costs of sprinkler systems more than for LE drip systems because the cost of solar panels (due to high power needs) is such a large proportion of the total capital cost for a sprinkler system. One implication of this observation is that a single LE drip system could work well for a wide variety of farm profiles without large fluctuations in the number of solar panels needed. This is important from a distribution and marketing standpoint because companies and NGOs often prefer to standardize the systems they sell or provide.

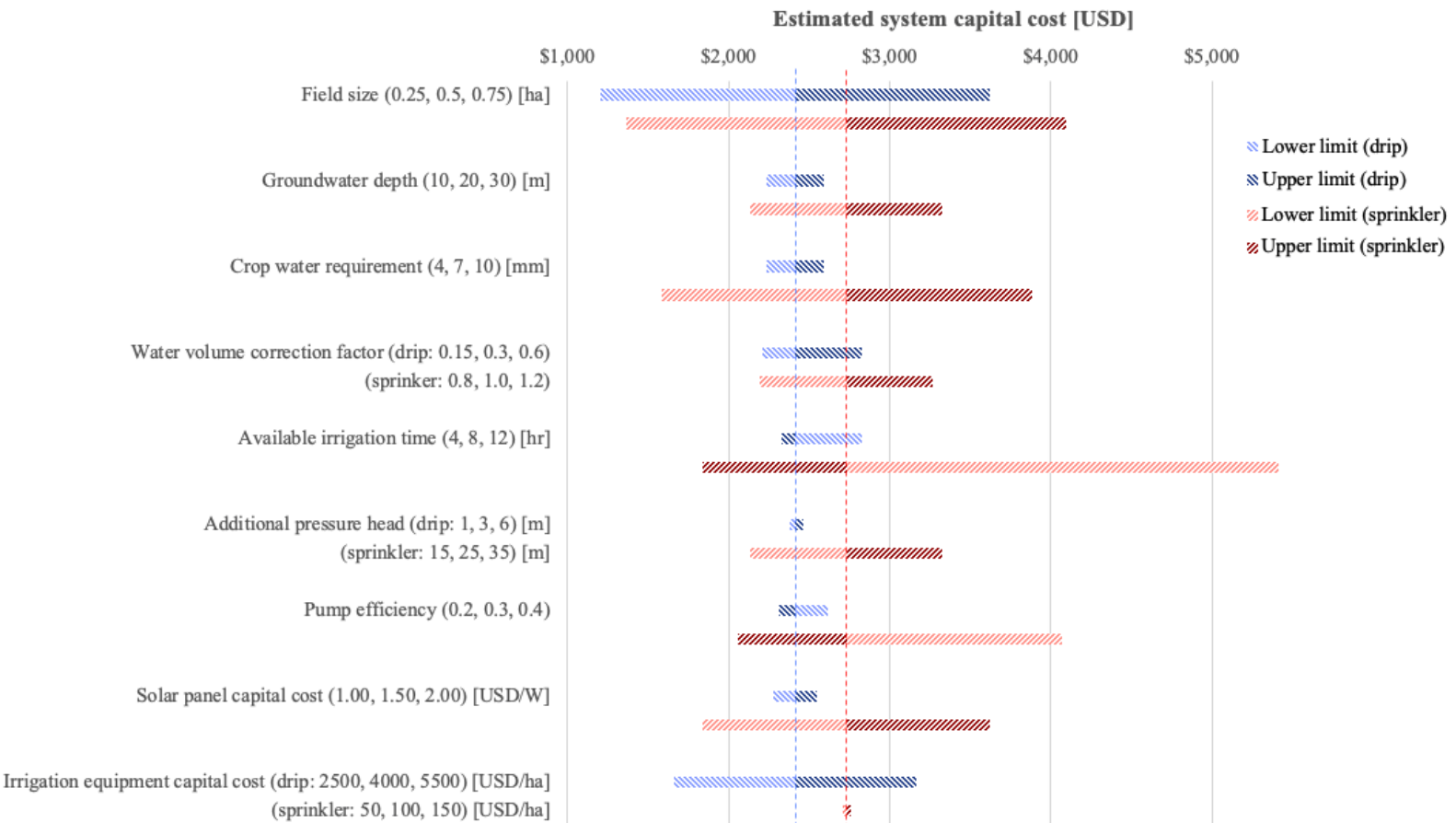

Figure 2. Sensitivity analysis results showing impact of farm profile input parameters on capital cost of LE drip (blue) and sprinkler (red) irrigation systems. Lower limit, baseline value, and upper limit bounds are listed next to each parameter

From Figure 2, the pump efficiency is inversely proportional to the power requirement and capital cost. For more efficient systems, less power is required to compensate for losses. This result highlights the need for the design of a higher efficiency pump that can be incorporated into a low-cost LE drip system. The available irrigation time, which is an important parameter to consider from a user-centred perspective, is also inversely proportional to the power needed. For longer available irrigation times, lower flow rates can be used and less power is required. The results from farmer interviews revealed that farmers care a great deal about the time they actively spend irrigating, but they are less concerned with how long the irrigation system itself runs. Drip irrigation in particular is an irrigation method that can require less of a farmer's active time than other methods if the farmer is trained properly. This suggests that there is potential for a low flow rate, lower cost LE drip irrigation system if that system doesn't have to be actively operated by the farmer for the entire irrigation time, which could be achieved if the farmer has proper training on drip irrigation.

Sprinkler systems are much less sensitive to irrigation equipment capital costs than LE drip irrigation systems. The cost of sprinkler equipment is relatively so low that it doesn't drive the cost of the system as the much higher capital cost of the solar panels does. Drip irrigation equipment costs make up a much larger proportion of the LE drip system total capital cost, so large fluctuations in drip equipment cost have a large effect on the total system cost. If LE drip were available in SSA at the lower price limit assumed in the sensitivity analysis, its baseline cost of 2410 USD could decrease by $28 \%$ to 1660 USD. Sprinklers at the lower price limit would decrease by only $1 \%$, from 2730 USD to 2700 USD.

It was assumed that farmers were much more likely to overwater their crops while using LE drip than to underwater. The $V C F$ for drip irrigation could be higher than 0.3 , particularly if farmers aren't 
trained to use drip irrigation properly. If farmers are properly trained to deliver the appropriate amount of water, their power system can be sized to account for a $V C F$ of 0.3 . If farmers aren't trained properly and tend to overwater their crops, their power system needs to be more expensive to account for higher flow rates to meet a higher water demand.

One possible way to promote proper training for LE drip irrigation could be to design an irrigation system and corresponding growth plan that aids in the training of farmers. Such a plan could potentially increase LE drip adoption by improving the irrigation skills of farmers while reducing the cost barriers to the technology. For example, a small system consisting of a pump, solar panel, and three butterfly sprinklers could teach a farmer equipment maintenance techniques because sprinklers on a pipe network require more care than buckets and hoses. Once the farmer has earned revenue from this smaller system, they could upgrade their pump, use the same solar panel, and purchase the beginnings of a LE drip network, allowing them to expand irrigated land further and to more easily maintain the LE drip equipment. Future work will address the feasibility of this concept.

Figure 2 demonstrates that there may be many potential possibilities to achieve low-cost irrigation systems in SSA. The baseline LE drip system capital cost is lower than that of sprinkler systems in this first-order estimation, but there are large fluctuations in the estimated sprinkler system capital costs, causing sprinklers to cost less than LE drip for certain farm profiles. For example, a farmer could use the baseline LE drip system, or they could use a sprinkler system but grow crops with a CWR of $4 \mathrm{~mm}$, all for a lower system cost. However, this crop with a lower CWR could sell for less in the local market, an effect not captured in the current model. Further research is needed to understand the many expansion plans and growth strategies that farmers could take to achieve low-cost irrigation on their farms and how these plans impact the technical design of irrigation systems. These results demonstrate a need to understand the specific design requirements in SSA and to design a system tailored to meet those needs

\section{Conclusions and future work}

The objective of this work was to explore the potential for low-energy drip emitter technology to have a positive impact on the SSA irrigation market for solar-powered drip irrigation by reducing the cost barriers to drip irrigation systems. To accomplish this, the design space was examined from both a usercentred perspective and an engineering lens. First, interviews with farmers and key market stakeholders in Kenya, Ethiopia, and Zambia were conducted to understand user preferences concerning the trade-off between potential cost savings and longer daily irritation times (associated with lower flow rates). Second, using conclusions from these interviews and values from literature, a model was then created to compare the power needed by and the capital cost of LE drip and impact sprinkler irrigation systems given baseline farm profile inputs. From these two perspectives, it was concluded that:

- Proper training on drip irrigation equipment may aid in successful adoption

- Some farmers are willing to use irrigation systems with low flow rates if it does not increase the time they actively spend irrigating

- Farmers may be willing to expand their irrigated area at the cost of increased irrigation times

- There is an energetic benefit to using LE drip irrigation, which results in lower system capital costs for certain farm profiles in SSA compared to those of impact sprinkler systems

- LE drip irrigation systems are much less sensitive to changes in input parameters that affect their power needs (groundwater depths, crop water requirements, available irrigation time, pump efficiency, and solar panel capital cost) than sprinkler irrigation systems

- There are many possible farm profiles that capable of achieving relatively low-cost LE drip or sprinkler irrigation systems in SSA; further research is needed to understand the growth strategies that farmers might take in order to achieve profitable irrigation on their farms.

The results presented here demonstrate that there is some potential for low-energy drip emitters to be an enabling technology for solar-powered drip irrigation in SSA, and that the design space around LE drip irrigation in SSA should be explored further. This work suggested that it may be possible to develop low-cost LE drip irrigation systems. From that, it was hypothesized that growth strategies might help farmers learn to effectively use the equipment, supporting their successful adoption in SSA. 
Future work will include conducting additional interviews with potential users and stakeholders. Model additions will incorporate a hydraulics model to more accurately predict the additional pressure head needed to pressurize the LE drip or sprinkler equipment and will expand to include additional irrigation methods for comparison (e.g. hose, furrow, hand pump, or bucket irrigation). Future versions will also include maintenance and labour costs associated with the various irrigation methods, estimate expected revenue and profits to understand potential pay back periods, and investigate potential expansion plans and growth strategies for farmers to aim to maximize profit in the shortest amount of time.

This work takes an initial step in understanding the potential for LE drip irrigation systems in SSA, justifying additional analysis. Understanding cost trade-offs, growth strategies, and user-centred design requirements will inform the design of future novel irrigation systems tailored to the SSA market.

\section{References}

Ali, B. (2018), "Comparative assessment of the feasibility for solar irrigation pumps in Sudan", Renewable and Sustainable Energy Reviews, Vol. 81, pp. 413-420.

Allen, R. et al. (1998), FAO Irrigation and Drainage Paper No. 56, Rome, p. 333.

Amede, T. (2015), "Technical and institutional attributes constraining the performance of small-scale irrigation in Ethiopia”, Water Resources and Rural Development, Vol. 6, pp. 78-91.

Blank, H.G., Mutero, C.M. and Murray-Rust, H. (Eds.). (2002), The Changing Face of Irrigation in Kenya: Opportunities for Anticipating Changes in Eastern and Southern Africa, International Water Management Institute, Colombo, Sri Lanka.

Burney, J. et al. (2010), "Solar-powered drip irrigation enhances food security in the Sudano-Sahel", Proceedings of the National Academy of Sciences, Vol. 107 No. 5, pp. 1848-1853.

FAO, IFAD, UNICEF, WFP and WHO (Eds.). (2017), The State of Food Security and Nutrition in the World 2017: Building Resilience for Peace and Food Security, FAO, Rome.

"Futurepump". (2020), Futurepump, available at: https://futurepump.com/.

Grant, F.R. (2019), Development and Validation of a Systems-Level Cost Optimization Tool for Solar-Powered Drip Irrigation Systems for Smallholder Farms, MIT, Cambridge, MA.

Hagos, F. et al. (2012), “Agricultural water management and poverty in Ethiopia”, Agricultural Economics, Vol. 43, pp. 99-111.

Hartung, H. and Pluschke, L. (2018), The Benefits and Risks of Solar Powered Irrigation, FAO and GIZ, p. 87.

Kebede, H. and Birru, E. (2018), Guideline for Irrigation Agronomy, Ministry of Agriculture and Natural Resources Small-Scale Irrigation Development Directorate, Addis Ababa, Ethiopia.

Mati, B.M. (2008), "Capacity development for smallholder irrigation in Kenya", Irrigation and Drainage, Vol. 57 No. 3, pp. 332-340.

Ngigi, S.N. et al. (2001), Low-Cost Irrigation for Poverty Reduction: An Evaluation of Low-Head Drip Irrigation Technologies in Kenya, Annual report, International Water Management Institute (IWMI), Colombo, Sri Lanka, pp. 23-29.

Otoo, M. et al. (n.d.). "Business model scenarios and suitability: Smallholder solar pump-based irrigation in Ethiopia", p. 71.

Patil, S. (2019), "Skype conversation with Sachin Patil", 9 September.

Pavelic, P. et al. (2013), "Smallholder groundwater irrigation in Sub-Saharan Africa: country-level estimates of development potential”, Water International, Vol. 38 No. 4, pp. 392-407.

Schmitter, P. et al. (2018), "Suitability mapping framework for solar photovoltaic pumps for smallholder farmers in sub-Saharan Africa”, Applied Geography, Vol. 94, pp. 41-57.

Shah, T., Verma, S. and Pavelic, P. (2013), "Understanding smallholder irrigation in Sub-Saharan Africa: results of a sample survey from nine countries", Water International, Vol. 38 No. 6, pp. 809-826.

Shamshery, P. and Winter, A.G. (2018), "Shape and Form Optimization of On-Line Pressure-Compensating Drip Emitters to Achieve Lower Activation Pressure", Journal of Mechanical Design, Vol. 140 No. 3, p. 035001.

Sheline, C. (2019), Lowering the Cost of Solar-Powered Drip Irrigation Systems for Smallholder Farmers Through Systems-Level Modeling, Optimization, and Field Testing, MIT, Cambridge, MA.

Sokol, J. et al. (2019), "Energy Reduction and Uniformity of Low-Pressure Online Drip Irrigation Emitters in Field Tests", Water, Vol. 11 No. 6, p. 1195.

Sokol, J., Sheline, C. and Grant, F. (2018), "Development of a System Model for Low-Cost, Solar-Powered Drip Irrigation Systems in the MENA Region”, p. 12.

"SunCulture Products", (2020), SunCulture Products, available at: http://www.sunculture.com/index.php/products/

Yamegueu, D., Alokore, Y. and Corso, G. (2019), "Potential of microfinanced solar water pumping systems for irrigation in rural areas of Burkina Faso", Energy, Sustainability and Society, Vol. 9, p. 1. 